nante que va a sus negocios, a leer lo que a él se le antojó escribir o en alabança o en vituperio de aquel difunto. Si va a caballo, ¿cómo se ha de apear, o quién le ha de tener la mula? Y si la sepultura está en iglesia, claro está que no se ha hecho el epitafio para los que van en coche. Si el tal caminante va a pie, ¿para qué se ha de detener a lo que no le importa, para llegar más tarde a la posada?

César-Esso, y lo de los antiguos, "séale la tierra leve", me tiene también cansado. Pues al difunto no se le puede dar nada de que le echen encima un monte o un necio, que es la cosa más pesada (p. 363).

Vemos, a la luz de estos ejemplos, desde un ángulo diferente las escenas 2 y 3 del acto IV. Si las unimos a todos los comentarios, críticas y parodias sobre las convenciones literarias que encontramos en el texto de La Dorotea, no resultan ya digresiones eruditas; más bien debe considerárselas como la culminación del tema esencial de la obra: la naturaleza problemática de la literatura. Por la extensión de estas escenas, por la manera concentrada en que aparecen allí tratados temas como poesía, lenguaje, alusión vs. verdad, y por el lugar que tienen en la obra, Lope presenta en ellas, en verdad, una "academia que enseña algo".

Washington University, St. Louis Missouri.

SANDRA M. FOA

\title{
DOS FUENTES DEL PRIMER SOLILOQUIO DE SEGISMUNDO
}

Dice Alfonso Reyes, en un magistral estudio, que el primer soliloquio de Segismundo en La vida es sueño contiene dos ideas centrales: "concéntrase la primera en la frase «el delito mayor del hombre es haber nacido», y la segunda en el estribillo $* \mathrm{Y}$ teniendo yo más alma tengo menos libertad». La primera idea -compendio del pesimismo práctico- es, por lo menos, tan antigua como la fábula de Sileno y Midas, recuerda las lamentaciones de Job... [y] fácilmente se transfor. ma, a poco que el espíritu cristiano la rectifique, en el tema del desengaño" 1. Estudiar esta idea requeriría, según A. Reyes, un examen filosófico de toda la tradición escrita y oral del desengaño español, tarea a la que renuncia en favor de un estudio minucioso de las manifesta. ciones de la segunda idea, la comparación negativa del hombre con los demás seres de la naturaleza. Sin embargo, a veces las dos ideas han aparecido juntas, y es de suponer que Calderón tuviese en cuenta uno o más de los textos consolidados al escribir el soliloquio de Segismundo. Entre éstos se encuentran el Sermón de Erasmo ${ }^{2}$, y especialmente un pasaje de la Traducción de los libros de Caio Plinio Segundo de la

1 Alfonso Reyes, "Un tema de La vida es sueño", Obras completas, t. 6, Mé. xico, 1957, pp. 185-186.

2 "Sermón de la infinita misericordia de Dios" (1524), trad. esp. anónima, 1528, cit. por Marcel Batalllon, Erasmo y España, México, 1966, p. 289. 
Historia natural de los animales, hecha por el licenciado Jerónimo de Huerta (Alcalá, 1602-1603), que dice en parte: "Las otras fieras y animales que nacen entre nosotros quedan libres en naciendo, y el hombre - nacido para señor dellos- llorando está, ligado de pies y manos, y como por mal agüero comiença su vida por prisiones y dolor; y este mal no le viene por otro error, sino por aver nacido" 3 .

Hay otro texto donde se reúnen las dos ideas, que tiene además otro paralelo con el monólogo, que hasta ahora no ha sido aducido en este respecto. Se trata de una parte del primer capítulo de La des. ordenada codicia de los bienes ajenos de Carlos García, publicado en París en 1619 *. Por la fecha, más próxima a la comedia de Calderón, y por el desarrollo bastante extenso de las ideas sobre el tema, es plausible que Calderón conociera este libro.

En ese primer capítulo, García compara la prisión con el infierno, y subraya la importancia de la libertad del hombre como bien elemental: "A la pena esencial del infierno, que es la privación de la Divina Esencia, corresponde en la prisión la privación de la libertad, a la cual con justo título podemos llamar pena esencial, por ser la reina de todas cuantas aprensiones y motivos de dolor pueden afligir un honrado entendimiento" (p. 31). Esta ecuación infierno-prisión halla su expresión dramática en La vida es sueño: Segismundo aparece por primera vez saliendo de la puerta de un edificio en lo profundo de un valle que es un "confuso laberinto" (v. 6) ${ }^{5}$ (como dice Rosaura: "La puerta / (mejor diré funesta boca) abierta / está, y desde su centro / nace la noche, pues la engendra dentro"; vs. 69-72). Esta representación del infierno es también "una prisión oscura / que es de un vivo cadáver sepultura" (vs. 93-94). Presentar la prisión como el infierno permite a Calderón dar más relieve a la idea del pecado original. Segismundo nace simbólicamente del infierno, y si no consigue emplear su libre albedrío, el infierno será también su destino. La idea de que "el mayor crimen del hombre es haber nacido" no tiene en el Sermón de Erasmo ni en la traducción de Plinio el sentido de pecado original; es posible, pues, que la imagen de Carlos García haya influido en la creación de Calderón.

Sigue García: "Y así como en aquella [infernal habitación], estando el alma privada de Dios, lo está también de todos los placeres del mundo, de la propia suerte en [la prisión] no goza de cosa que tenga sombra de contento; porque, aunque un encarcelado anduviese vestido de púrpura, servido como un rey, sustentado en los más delicados manjares del mundo, su cámara cubierta de brocado, entretenido con todo

3 Cit. por A. REYes, op. cit., pp. 217-218.

4 Carlos García, La desordenada codicia de los bienes ajenos; antigüedad y nobleza de los ladrones, ed. Fernando Gutiérrez, Barcelona, 1959. Quiero agradecer al profesor Howard Mancing por haberme facilitado este dato.

5 García utiliza términos parecidos para describir el infierno: "un infinito abis. mo de confusión y dolor" (p. 28); "caos, desorden, confusión" (p. 28); "no hay orden ninguno" (p. 29); "la extremada confusión del infierno" (p. 31); etc. Para las citas de Calderón empleo la edición de Albert E. Sloman de La vida es sueño, Manchester, 1961. 
género de música, visitado de parientes y amigos y lo demás que pue. de desearse, no tendría el mínimo consuelo del mundo, antes bien lo tendrá menos, porque todas estas cosas no sirven, que de despertalle más el apetito a desear lo que los otros gozan y él no puede alcanzar: de donde viene a aumentarse la privación y por consiguiente la pena" (op. cit., p. 31). Calderón pospone esta idea, que presenta en términos del durmiente despierto, hasta el segundo acto, aunque es clara desde el principio la estirpe real de Segismundo: su torre-prisión es también "un palacio" (v. 57). Y la idea básica es la misma. Segismundo no puede gozar de los deleites del palacio real porque no es libre; su libertad es aparente, y esa falta se expresa en su reacción fiera. Hasta humanizarse, no saldrá de su prisión (psicológica), y continuará siendo "monstruo humano..., una fiera de los hombres" (vs. 209-212). (Es curioso que Carlos García emplee casi la misma frase, un "fiero monstruo", para describir a su rey preso; op. cit., p. 31).

En el pasaje clave que sigue, García subraya la importancia de la libertad de una manera parecida a la del primer monólogo de Segismundo. Dice García: "Y siendo la libertad la más preciosa joya del alma, y la mayor perfección que el inmenso Autor del universo plantó en la criatura racional, es cierto que su privación será la más perversa e insoportable de todas... [y] trae al hombre a tal extremo que se aborrezca a sí mismo, su ser, su constitución y estado... [Su desespe. ración] le va apurando y consumiendo con el fuego de la impaciencia, de tal suerte que le saca del ser racional, y le reduce al de bestia bruta, y entre éstas, a la más baja e ínfima especie, pues suspirando la libertad, invidia al ave que vuela, al perro que ladra y la hormiga que camina, deseando ser uno dellos. $Y$ no para aquí el veneno deste fiera animal; porque apretando esta furiosa aprensión a un pobre encarcelado, no solamente le saca del orden y categoría de los animales, deseando ser árbol, estatua o piedra, pero le reduce al nada, pesándole de haber nacido en el mundo. De donde se ve claramente que, haciendo la privación de la libertad en el hombre un cambio tan desdichado como es precipitalle de lo más alto y perfecto de su inclinación y apetito a lo más bajo e ínfimo, y de la imagen y semejanza de Dios al nada, es la más fuerte y rigurosa pena que se puede imaginar y la que puntualmente retrata la esencia del infierno" (ibid., pp. 31-33). Se reúnen aquí los dos temas del monólogo: las ventajas de los animales y otros seres naturales sobre el hombre sin libertad, y el dolor de haber nacido, todo presentado de manera más extrema y amplia que en los comentaristas anteriores. El tratamiento barroco de los temas nada-Dios, infiernocielo, bestia-ser humano libre tiene su paralelo en la visión de Calderón. La libertad de que habla García no es meramente la libertad corporal; es la libertad esencial, el libre albedrío. En efecto, otro pasaje de García, el último que citaremos, puede servir como explicación de la concepción fundamental de $L a$ vida es sueño: "Que la libertad sea la que encamina y dirige las acciones del hombre a varios y diversos fines, sin violencia, con gusto, escogiendo y mandando, la experiencia lo enseña: en lo cual el Supremo Artífice quiso diferenciar al hombre de los animales brutos, el fin de los cuales se alcanza por un instinto 
natural, que les lleva, como por el cabestro, al apetito y complacencia de él. Y que la libertad sea tan poderosa que haga al hombre tan absoluto y señor que, habiéndole propuesto el entendimiento lo bueno, perfecto, honesto y deleitable, pueda determinarse a amallo, y también a no hacello, sin que pueda pedille residencia de este absoluto imperio otra que Dios, la natural filosofía lo dice; como también por la absoluta independencia de sus acciones haya el hombre alcanzado la imagen y semejanza de Dios, y con esto la perfección más subida de punto que podía pretender" (ibid., p. 32). Así, cuando Segismundo renuncia a Rosaura, usa totalmente su libre albedrío: ha aprendido a "amallo, y también a no hacello".

Resulta, creo, claro que el texto de García bien podría haber influido en la comedia de Calderón. La representación de la prisión como el infierno, con la idea concomitante de que el nacer es un crimen; el ejemplo de un rey que no puede gozar de las ventajas de su estado por faltarle la libertad (corporal y voluntaria); la comparación desventajosa del hombre con los seres naturales; la insistencia en la libertad, que, al hacer posible que el hombre domine sus instintos, le permite elevarse desde la nada hasta representar la imagen de Dios; y la expresión cósmica de todas estas ideas, todo sugiere la familiaridad de Calderón con la obra de Carlos García.

Pero las influencias sobre Calderón no se limitan a las ideas; tam. bién incluyen elementos formales que se imponen cada vez más para la presentación de estas ideas en la literatura. Buchanan, Monner Sans ${ }^{6}$ y Reyes han presentado textos poéticos, la mayoría sacados de obras dramáticas, que muestran una clara evolución del tema - comparación del hombre con los seres naturales- hasta su expresión suprema en La vida es sueño. Quisiera añadir un ejemplo desconocido, el más cercano a la fecha de la comedia de Calderón, y el que seguramente sirvió de modelo inmediato al dramaturgo: el de don Antonio Sigler de Huerta.

La primera de las siete décimas (vs. 103-172) expone el tema del nacer como crimen, y en la segunda Segismundo se pregunta por qué recibe él más pena por este crimen que el resto de la humanidad. Las cinco estrofas siguientes desarrollan el tema que nos ocupa ahora: la inferioridad del hombre en comparación a los otros seres naturales. Segismundo compara su propio estado con el de un pájaro, una fiera, un pez, y un arroyo, terminando cada décima con el estribillo (con variantes): " $\mathrm{Y}$ teniendo yo más alma,/ tengo menos libertad?" La última estrofa concluye con una recapitulación de los cuatro seres tratados antes por separado.

Veamos ahora los antecedentes poéticos más parecidos al soliloquio de Segismundo. En Barlán y Josefá $(1611)^{\top}$ de Lope, un preso proclama su inocencia y se compara al corderillo y al ave, que gozan de una libertad que él no tiene.

6 Milton Buchanan, "Segismundo's soliloquy on liberty in Calderón's La vida es sueño", MLN, 23 (1908), 240-253; Ricardo MonNer Sans, "Soliloquio de Segismundo", Nosotros, 44 (1924), 27-36.

7 El texto de Lope está citado por Buchanan, art. cit., pp. 241-243. 
Dos pasajes de Lo que ha de ser (1624) del mismo autor presentan el tema de un príncipe encarcelado aunque inocente; en el primero hay un verso importante para el tema que desarrollo: "¿Qué hice en naciendo yo?"; en el segundo se habla de la libertad del "más feroz animal" y del "más pobre pastor".

De un soneto de Guillén de Castro que se halla en El Narciso en su opinión, dice Buchanan (art. cit., p. 247) que "apenas se puede dudar de que Calderón lo haya tenido frente a si cuando compuso su versión". Creo más probable que el soneto haya influido sobre Sigler de Huerta, y que, por tanto, la influencia de Castro en La vida es sueño sea de segunda mano. Digno de atención en el soneto es el número de animales que se enumeran:

Apenas tiene pluma el avecilla,

Cuando pone en los vientos el cuidado;

El más menudo pez del mar salado

Suele atreverse a su arenosa orilla.

Deja el monte la tierna cervatilla,

$\mathrm{Y}$ aunque con su peligro pace el prado,

Las útiles defensas del ganado

Pierde tal vez la mansa corderilla.

Sube al aire la tierra más pesada,

Sale de madre el más pequeño río,

El cobarde mayor saca la espada.

La menor esperanza finge lirio,

Y solamente la mujer honrada

Tiene sin libertad el albedrio.

Los textos de Lope y de Castro son de interés, pero en las obras dramáticas de Mira de Amescua hallamos mayor número de elaboraciones del tópico de la inferioridad natural del hombre. Mira es el primero que empleó la décima a este respecto y el primero que incorporó un estribillo. Los ejemplos pueden verse en el estudio de William$\operatorname{sen}^{8}$; me limito a notar dos textos que me parecen más importantes, y que pertenecen a comedias de 1628 (No hay dicha ni desdicha hasta la muerte) y 1630 (Galán, valiente y discreto). En ambos las décimas tienen estribillos, y éstos empiezan con frases participiales con el sujeto yo. El pasaje más temprano, de tres décimas, contiene el conjunto de imágenes de planta, de agua y de pájaro, y este estribillo: " $Y Y$ siendo yo racional, / es eterna mi tristeza!" $\mathrm{El}$ otro soliloquio, de dos décimas, alude sólo al pájaro (tórtola) y al animal (leona), pero la famosa pregunta de Segismundo se prefigura claramente en el estribillo con su aposición de más / menos: "¿Teniendo yo más amor, / tengo menos esperanza?" 9.

8 Véase Vern G. Whllamsen, "The development of a Décima in Mira de Amescua's theater", $B C, 22$ (1970), 32-36.

9 Los textos están citados por Williamsen, art. cit., pp. 34-35. 
Así pues, Lope siempre relaciona el tópico de la inferioridad del hombre con un encarcelamiento real. En el soneto de Guillén de Castro la falta de libertad se basa en la voluntad, no en el cuerpo, y todo el orden natural - la tierra, el río, el animal, el pájaro y el hombre- se contrasta con la mujer. Además, la idea de que la pérdida de la libertad afecta al libre albedrío es innovación de Guillén de Castro. Aunque en las décimas de Mira no se halla el tema de la libertad, otros elementos son muy parecidos a los del monólogo de Segismundo: el uso de la décima, el estribillo final de dos versos con una frase participial con yo como sujeto, y las imágenes de planta, de animal y de agua.

La fuente nueva data de 1632, sólo tres años antes de la fecha nor. malmente asignada a $L a$ vida es sueño. Es un pasaje que aparece en la primera comedia de don Antonio Sigler de Huerta, Las doncellas de Madrid ${ }^{10}$. Se trata de la respuesta de doña Ana de Vargas a la sugerencia de su hermana Inés para que se vuelva más racional y menos emocional:

Para querer no hay razón; sin razón se ha de querer. Que la que llega a poner en razón la voluntad vendrá con facilidad de querer aborrecer. Fuente comienza a nacer entre juncia y espadaña, hija de aquella montaña que apenas se deja ver, y la que fuente fue ayer ya es undosa majestad, peligrosa majestad más libre la aclamó río, ¿y yo con más albedrío, tengo menos libertad?

Ya en la rama, ya en la flor nace ya bajel de plumas, golfo mayor con espumas, matizado ruiseñor; Alegre canta su amor en la dulce variedad; docta su simplicidad, el calor huye y el frío, ¿y yo con más albedrio, tengo menos voluntad?

Libre discurre una fiera por el monte o por el llano. Lo que perdona su mano mata su vista severa.

Rey de la campaña, altera con atrevida impiedad cuanto alberga la piedad contra el hielo y el estío, ¿y yo con más albedrio, tengo menos voluntad?

Pues amor no es de manera que le pueda corregir, dejarme, sabré morir, que no seré la primera. Libertad goza cualquiera, y el dulce conformidad. Es común esta piedad a un ave, a una fiera, a un río, ¿y yo con más albedrío, tengo menos libertad?

10 ANronio Sigler de Huerta, Las doncellas de Madrid, ff. 10r-11r. Esta comedia inédita se halla en un manuscrito único del siglo diecisiete en la Biblioteca Vaticana, Barberini Lat. 3487 (con la anotación: "jamás representada, sacada del original"). Al final del texto hay esta anotación: "acabóse de escribir esta come. dia a 30 de mayo 1632 y tiene toda la comedia 2641 versos". La única referencia a esta obra está en Para todos (1632) de Juan Pérez de Montalbán, quien dice de Sigler de Huerta: "está acabando una comedia, que intitula las Donzellas de Ma. drid" (cito de la edición de 1681 , p. 514). Sobre el autor véase E. M. Wirson, "Calderon's enemy: Don Antonio Sigler de Huerta", $M L N, 81$ (1966), 225-231. 
En estos versos, la falta de valor estético se compensa con el interés histórico. Vale la pena notar varios aspectos, aparte de las semejanzas formales obvias (décimas y el estribillo): 1) el estribillo tiene más de una forma, como el de La vida es sueño. Es más, una de las variantes coincide exactamente con el estribillo que usa Calderón: “¿y yo, con más albedrío, / tengo menos libertad?"; 2) sólo Sigler de Huerta, y Mira en un texto de 1618 (?) ${ }^{11}$, recapitulan sus imágenes como lo hace Calderón; 3) las cualidades de las entidades con que el ser humano se compara son notablemente análogas en las obras de Sigler de Huerta y de Calderón. Compárense los textos que cito a continuación:

Sigler de Huerta

Fuente comienza a nacer

entre juncia y espadaña, hija de aquella montaña que apenas se dexa ver, y la que fuente fue ayer ya es undosa majestad; peligrosa majestad [sic] más libre le aclamó río; ¿y yo con más albedrio, tengo menos libertad?

\section{Calderón}

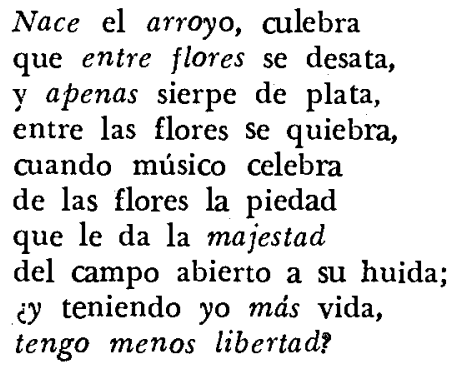

Así como el pájaro es para Calderón "flor de pluma, / o ramillete con alas", para Sigler de la Huerta: "bajel de plumas, / golfo mayor con espumas", metáfora que Calderón usa para describir al pez ("bajel de escamas"). Los dos autores resaltan la crueldad como el atributo primario de la fiera, aunque Sigler de Huerta pone de relieve su libertad y Calderón sus instintos bestiales.

Hay, desde luego, diferencias importantes. No tiene el discurso de doña Ana la intensidad del de Segismundo, porque la pérdida de libertad es sólo figurada y porque falta el tema del crimen esencial del hombre. Como en el soneto de Guillén de Castro, el locutor es una mujer. Es probable que el soneto influyera en Sigler de Huerta, ya que se refiere específicamente al albedrio y a la libertad. La serie de Sigler, como la de Mira, omite el pez; también el orden de la presentación es distinto. Sigler de Huerta progresa del agua, al pájaro, a la bestia. Calderón invierte, en parte, ese orden: agua, pez, bestia, pájaro.

No es probable que Las doncellas de Madrid haya sido la única fuente poética de Calderón. El antecedente de Lope por un lado, y, por otro, las muchas reminicencias de Mira en el teatro de Calderón indican que éste habría conocido al menos uno de los repetidos trata. mientos de Mira del tema de la superioridad de los otros seres naturales sobre el hombre. Sin embargo, en Mira no hay, en cuanto a estos temas, nada que no se encuentre en Sigler de Huerta. También el modelo de Guillén de Castro puede haber llegado a Calderón a tra-

$11 \mathrm{El}$ rico avariento; transcrito por WILLIAMSEN, art. cit., p. 33. 
vés de Sigler de Huerta; lo que parece seguro es la influencia de éste en La vida es sueño.

Quizá, la influencia podría haber sido al revés; que La vida es sueño se haya escrito antes que Las doncellas de Madrid, terminada el 30 de mayo, 1632. Hoy se suele aceptar la fecha de $c a .1635$ para la composición de la comedia de Calderón, porque, según Cotarelo y Sloman, deriva de la comedia de Calderón y Antonio Coello Los yerros de naturaleza, licenciada en 1634, y porque fue publicada en $1636^{12}$. Sin embargo, no veo razones terminantes en el estudio de Sloman que permitan esta conclusión, y es de notar que otros investigadores - Nortthup, Schevill, y de cierta manera Juliá Martínez- creyeron que Los yerros de naturaleza está basada en $L a$ vida es sueño ${ }^{13}$. Además, Hilborn, al analizar la versificación de La vida es sueño, le asignó la fecha 1631-32 ${ }^{14}$.

Sin embargo, dos aspectos de los monólogos parecen indicar la prioridad de Sigler de Huerta. Primero, este tipo de poema en décimas con estribillo tiende a la monotonía, puesto que la segunda mitad de todas las estrofas contiene las mismas dos rimas. Sólo Calderón supera este problema variando las rimas del estribillo. Si Calderón hubiera sido el modelo de Sigler de Huerta, no se explica por qué se reduce éste a la práctica menos satisfactoria de Mira. Luego, si Mira hubiera sido modelo de Sigler de Huerta, se entiende la ausencia del pez en su serie, ya que tampoco figura éste en las versiones de Mira. Pero si su fuente hubiera sido La vida es sueño, ¿para qué omitir el pez, que concuerda tan bien con el desarrollo del tema? Por ahora, entonces, prefiero aceptar la prioridad de Las doncellas de Madrid sobre La vida es sueño.

University of Huston.

Harold G. Jones

\section{UN ANÁLISIS DE “LO FATAL” DE RUBÉN DARIO}

"Lo fatal", los "Nocturnos", el "Poema de otoño", asi como otras composiciones de Cantos de vida y esperanza son poemas de meditación que caracterizan la etapa madura de la obra de Rubén Dario. Expresión de una pausa reflexiva ante el problema existencial, "Lo fa-

12 Emilo Cotarelo y Mori, Ensayo sobre la vida y obras de Calderón, Madrid, 1929, p. 150, nota. Albert E. Sloman, The dramatic craftsmanship of Calderon. His use of earlier plays, Oxford, 1958, pp. 250-251.

18 GeORge Tyler Northup, "Los yerros de naturaleza y aciertos de la fortuna, by Don Antonio Coello and Don Pedro Calderón de la Barca", $R R, 1$ (1910), 411-425; RUDOLPH Schevill, "Virtudes vencen señales and $L a$ vida es sueño", $H R$, 1 (1933), p. 191; Pedro Calderón y Antonio Coello, Yerros de naturaleza y aciertos de la fortuna, ed. E. Juliá Martínez, Madrid, 1930, p. 23.

14 Harry Warren Hilborn, $A$ chronology of the plays of D. Pedro Calderon de la Barca, Toronto, 1938, pp. 16-19. 